\title{
SOBRE LA FUNDAMENTACIÓN METATEÓRICA DE LA INVESTIGACIÓN LITERARIA
}

\author{
Manuel Maldonado Alemán
}

\begin{abstract}
This work starts from the necessity that literary investigation is supported in a metatheoretic reflection that in an exact way gives a reason and adjust its procedure, so that it can guarantee the necessity of cientific severity. This reflection must clarify how this theories and methods have to be conceptually molded, and stablish the general theoric-cientific points of view that must direct the practical investigation. In this way is an object of this work prevent, from a critic of the classic conception of the cientific theories and following the first notions of the structural conceptions of them, a metatheoretic basis of the literary investigation, as it has been applied in the Empirical Theory of Literature.
\end{abstract}

\section{INTRODUCCIÓN}

Desde diversas perspectivas se viene insistiendo en las últimas décadas que todo conocimiento humano, también el conocimiento científico, es una operación específica realizada por un sistema cognitivo, que depende estrictamente de la constitución biológica y proceso de socialización de ese sistema. Según este enfoque, el conocimiento y la observación no parten de la percepción pura y simple, pues ésta nunca es inmediata, sino más bien de un punto de vista determinado, de un problema previo que se pretende resolver, de una teoría subyacente que dirige la observación. Con la ayuda de teorías implícitas o explícitas, que pueden tener el carácter de conceptos, esquemas, marcos referenciales, modelos, sistemas, etc., el ser humano observa, describe o explica el mundo que le rodea, sistematizando y estructurando sus experiencias. Siempre será lo teórico, y no la observación, lo primordial en todo proceso cognitivo, sin que se dé la posibilidad de una observación, descripción o explicación pura o neutra ${ }^{1}$.

Esta primacía de lo teórico tiene validez incluso en doble sentido: las teorías no son sólo constitutivas del conocimiento, sino también del ámbito de experiencia al que se refiere ese conocimiento. Por un lado, determinan el modo específico de experimentar los fenómenos y, por otro, delimitan los fenómenos que van a ser objeto de conocimiento, es decir, seleccionan de todos los hechos potencialmente observables aquellos que son relevantes en relación con la cuestión teórica planteada. De ello se deduce que las teorías no encuentran su aplicación primera en el proceso de investigación o explicación de un determinado fenómeno, sino más bien en el proceso de su constitución: la 'realidad' tiene que ser prime-

\footnotetext{
${ }^{1}$ Cfr., a modo de ejemplo, Popper (1962: 104; 1964: 44; 1965: 46); Feyerabend (1970); Spinner (1974: 112); KnorrCetina (1984); Latour/ Woolgar (1986); Hacking (1988); Maturana (1982, 1989); Roth (1991, 1992a, 1992b); Schmidt (1994).
} 
ramente construida a la luz de una teoría, para poder ser posteriormente investigada o explicada también con la ayuda de teorías. Describir y explicar un determinado fenómeno significa, por tanto, insertarlo en una teoría en cuyo marco cobra sentido.

La investigación científica, como una forma especial de conocimiento, también se caracteriza por estar determinada teóricamente, es decir, sólo puede llevarse a cabo con la ayuda de teorías. Gracias a ellas, el científico constituye una determinada sección de la realidad y la describe y explica al construir relaciones entre los elementos y propiedades que le atribuye. No obstante, a diferencia de lo que ocurre en el conocimiento cotidiano, en la ciencia se exige que se expliciten y se sistematicen con claridad las teorías, conceptos y métodos que han servido de fundamento para la obtención de un determinado conocimiento. Merced a este requisito, los resultados de la investigación científica pueden ser comprobados intersubjetivamente. En el ámbito de los estudios literarios ello supone la necesidad de disponer, si éstos quieren alcanzar efectivamente una condición científica, de una teoría general explícita que actúe de fundamento regulador de su actividad investigadora y que garantice una mínima homogeneidad concepcional acerca de sus principios téricocientíficos más elementales. Es decir, la investigación literaria, a fin de garantizar el necesario rigor científico, deberá sustentarse en una reflexión metateórica que de manera precisa fundamente y regule su proceder. Esta reflexión tendrá que aclarar cómo deben modelarse conceptualmente sus teorías y métodos, y establecer los presupuestos y criterios teóricocientíficos generales que han de dirigir su práctica investigadora. De este modo esa investigación podría optar a alcanzar su legitimación científica. Precisamente, es objetivo de este trabajo presentar, a partir de una crítica a la concepción clásica de las teorías científicas y siguiendo los principios de la concepción estructural de las mismas, desarrollada por J. D. Sneed bajo la influencia de las propuestas realizadas por T. S. Kuhn, una fundamentación metateórica de la investigación literaria, según ha sido aplicada en el seno de la Teoría Empírica de la Literatura.

\section{LA CONCEPCIÓN CLÁSICA DE LAS TEORÍAS CIENTÍFICAS}

La teoría de la ciencia analítica ha tratado con notable entusiasmo de encontrar una solución adecuada a las cuestiones de qué es una teoría científica y cómo está estructurada una teoría científica, y ha elaborado en su vertiente carnapiana la denominada concepción clásica o estándar de las teorías, que viene ejerciendo una notable influencia en los estudios literarios ${ }^{2}$. En su obra Theorienstrukturen und Theoriendynamik, W. Stegmüller llama a la concepción clásica "statement view der Theorien" o también "Aussagenkonzeption der Theorien" (1973: 2), y expresa ya en esa denominación el elemento esencial de esta concepción: una teoría científica es un conjunto de enunciados, entendiendo por enunciado una entidad lingüística con significado. Al considerar las teorías como entidades lingüísticas, los representantes de la concepción clásica, entre ellos R. Carnap, H. Reichenbach, R. B. Braithwaite, E. Nagel y C. G. Hempel, aun manteniendo profundas diferencias en otras

\footnotetext{
2 Así, Ihwe (1972), van Dijk (1972), Mignolo (1978) y Groeben (1972, 1980, 1982), entre otros, utilizan en sus investigaciones este concepto de teoría científica. Vid. el capítulo 3 de este trabajo.
} 
cuestiones, entendían que las teorías científicas debían ser formuladas necesariamente tanto en un lenguaje específico como de un modo determinado comúnmente aceptados, a fin de que quedara garantizada su reconstrucción racional y su comprobabilidad intersubjetiva; es decir, consideraban imprescindible la elaboración de una forma canónica de formulación de teorías con validez universal. Siguiendo el modelo de las ciencias formales, se estableció que esa modalidad debería ser la formulación axiomática, concretamente la aplicada a las matemáticas por la escuela formalista de D. Hilbert y sus seguidores, la cual, al sistematizar la teoría, posibilita una relación lógico-deductiva entre los enunciados que la componen. Asimismo, se exigió que esa formulación se realizara en un lenguaje formal, pues sólo éste garantizaría una precisión adecuada. De esta manera, axiomatización y formalización fueron consideradas procedimientos indispensables en toda construcción teórica. En ese caso, completando la definición anterior, las teorías científicas estarían compuestas por un conjunto de enunciados sobre un determinado dominio de objetos, axiomatizado dentro de un lenguaje formal al modo de las teorías matemáticas.

Según la concepción clásica, la construcción de una teoría científica supone el intento de obtener un conjunto de enunciados verdaderos sobre un determinado dominio de objetos. Se exige, como hemos señalado, que los enunciados se sistematicen construyendo la teoría como un sistema axiomático-deductivo, es decir, como un cálculo formal. Ese cálculo ha de reflejar sintácticamente las relaciones lógicas de consecuencia entre las proposiciones expresadas por los enunciados. Además, para que los términos del cálculo adquieran un significado concreto y sus axiomas pasen a ser verdaderos o falsos, es necesario interpretar el sistema axiomático sobre algún dominio. Esta interpretación se obtiene si a las variables individuales que aparecen en los axiomas se les asignan determinados objetos de ese dominio y a los predicados se les atribuyen propiedades y relaciones. Así, por ejemplo, si en el enunciado elemental $\Lambda x(P x \rightarrow Q x)^{3}$ designamos para $P x$ ' $x$ es una novela', para $Q x$ ' $x$ está escrito en prosa' y para $x$ ' $x$ es un texto lingüístico', resulta la siguiente interpretación de ese enunciado formulada en lenguaje corriente: 'Para todo texto lingüístico se cumple: si ese texto es una novela, entonces está escrito en prosa'. Si tras la interpretación los axiomas se convierten en enunciados verdaderos, "d. h. stehen die zugeordneten Objekte in den durch die Axiome beschriebenen Beziehungen zueinander und haben sie die in den Axiomen behaupteten Eigenschaften" (Stegmüller 1973: 37), entonces se diría que el sistema de cosas, propiedades y relaciones en cuestión es un modelo del sistema axiomático.

La necesidad de interpretar el sistema axiomático y otorgarle a la teoría un carácter empírico obligó a distinguir en la construcción de toda teoría empírica dos niveles bien diferenciados: el observacional y el teórico, con sus correspondientes clases de enunciados. Así, el lenguaje global de la ciencia $L$ quedaría dicotomizado en dos sublenguajes: el observacional $L_{o}$ y el teórico $L_{t}$.

\footnotetext{
${ }^{3}$ Los signos y abreviaciones que emplearemos en este trabajo son los siguientes: $\wedge$ (conjuntor), $\Lambda$ (cuantificador universal), $\rightarrow$ (implicación), = (igualdad),$<$ (menor que), $\leq$ (menor o igual que), $\in$ (es elemento de), $\subseteq$ (está incluido en o es igual a), $/ /$ (conjunto), \langle\rangle (conjunto ordenado), $\langle v / \ldots$. (el coniunto de los $v$ tales aue).
} 
La parte de la teoría que aparece formulada en el lenguaje observacional $L_{o}$ contiene en primer lugar el vocabulario observacional $V_{o}$. $V_{o}$ designa la clase de los términos elementales de $L_{o}$ que componen el conjunto de sus constantes descriptivas. Se exige de esos términos que designen objetos o fenómenos observables, o bien, propiedades y relaciones observables de tales objetos o fenómenos (Carnap 1959: 32-33; 1960: 212). Estos términos elementales̀ son considerados constantes básicas, con cuya ayuda se introducen en $L_{o}$ los enunciados complejos mediante definiciones explícitas. Estos enunciados deben comprender el contenido empírico de los términos elementales, por lo que es necesario que se indique en $L_{o}$ las reglas de formación de los enunciados complejos y las reglas de deducción lógica. En definitiva, el componente observacional de la teoría se utilizaría para una descripción del objeto de investigación, realizada con independencia de toda construcción teórica.

Por su parte, el lenguaje teórico $L_{t}$ se concibe como un cálculo formal entre cuyos elementos existen determinadas relaciones lógicas. Este cálculo está compuesto en primer lugar por los términos téricos considerados primitivos que constituyen el vocabulario teórico $V_{t}$. No se requiere de estos términos que sean observacionales, ni que sean definibles explícitamente gracias a los términos de $V_{o}$. Son más bien constantes básicas no definidas, como por ejemplo los conceptos fundamentales de la física teórica 'masa', 'temperatura', etc. Con su ayuda y por medio de definiciones explícitas se infieren los restantes términos teóricos (Carnap 1959: 32-33; 1969: 233). Además, forman parte de $L_{t}$ la estructura lógica que se va a utilizar para formular y derivar proposiciones, y los axiomas elegidos para inferir los teoremas de la teoría.

En consecuencia, $L_{o}$ y $L_{t}$ sólo se diferencian en sus términos descriptivos: $L_{o}$ contiene, además de las reglas lógicas, términos observacionales, pero ningún término teórico, por lo que se considera independiente de la teoría y neutro. $L_{t}$, aparte de incluir igualmente enunciados lógicos, comprende necesariamente conceptos teóricos y de forma facultativa términos observacionales. Todo enunciado que contenga por lo menos un término teórico ha de considerarse un enunciado teórico, mientras que aquel que comprenda exclusivamente conceptos teóricos es un enunciado téorico puro. Por lo tanto, una teoría pura aparecerá formulada totalmente en el lenguaje $L_{t} \mathrm{y}$, debido a la carencia de contenido empírico, no es más que un mero cálculo sin conexión con la realidad.

El problema que surge de la dicotomización del lenguaje de la ciencia en $L_{o}$ y $L_{t}$ es aclarar de qué modo una teoría pura $T$ puede obtener el contenido empírico que la caracterice como teoría empírico-científica, es decir, como se puede establecer la relación entre $L_{o}$ y $L_{t}$. Se consideró que para ello era necesaria la interpretación de $T$ siguiendo las 'reglas de correlación o correspondencia' $C$, llamadas simplemente reglas- $C$, un término acuñado por $\mathrm{R}$. Carnap. La interpretación empírica de $T$ se realizaría, concretamente, construyendo enunciados mixtos que relacionen de forma regulada a la manera de un 'diccionario' algunos términos de $V_{t}$ con términos de $V_{o}$. Estos enunciados mixtos serían las reglas de correspondencia. Su función consiste, pues, en lo fundamental, en derivar enunciados de $L_{o}$ a partir de $L_{t}$, y viceversa, de modo que los términos teóricos reciban significado empírico. En la 
teoría interpretada quedarían conectados los dos sublenguajes $L_{t}$ y $L_{o}$ mediante las reglas- $C$, por lo que esa teoría puede caracterizarse con la conjunción $T \wedge C$ (Carnap 1969: 232 y ss.).

No obstante, un enunciado mixto que una conjuntivamente sólo términos teóricos y sólo términos observacionales no garantiza de por sí que esos términos teóricos reciban sentido empírico, como muestra el ejemplo '(el mundo es ontológicamente un carácter del existir mismo) ^ (el mar es azul)'. Una conjunción semejante no puede ser empleada como regla de correspondencia. Para que las reglas- $C$ cumplan su función de conceder significado empírico a los términos teóricos, necesitan ser completadas con principios de adecuación. La discusión acerca de estos principios evidenció la complejidad de este tema, en el que además faltó unanimidad desde un comienzo, quedando finalmente sin resolver en la concepción estándar de las teorías.

Por otra parte, los representantes de esta concepción de las teorías tuvieron enormes problemas para justificar la dicotomía 'lenguaje observacional/ lenguaje teórico', especialmente cuando se exigió que se ofrecieran criterios concretos de atribución del predicado 'observable' a objetos, fenómenos o relaciones. El propio R. Carnap tuvo que reconocer que no se puede trazar objetivamente una línea exacta de demarcación entre lo observable y lo no observable, lo que supuso que, en definitiva, la vaguedad inicial de la dicotomización del lenguaje científico no pudiera ser superada. Estos problemas motivaron que la dicotomía $L_{d} L_{t}$ comenzara a ser seriamente cuestionada, incluso en el seno mismo de la concepción clásica, al no poder ofrecerse con precisión unos criterios claros de demarcación. C. G. Hempel fue uno de los primeros que se opuso a la concepción de 'observable' como un predicado metalingüístico monádico del tipo 'el término $t$ es un predicado observacional'. En su opinión, ese predicado es, en realidad, un predicado relacional de la forma 'el término $t$ es un predicado observacional para la persona $p$ ', por lo que siempre que se hable de observabilidad habría que precisar con relación a quien algo es observable (1973: 372). La consideración de lo que es observable no sólo depende de las capacidades biológicas y psicológicas del observador, sino en especial de las aptitudes lingüísticas y científicas que éste haya adquirido. El concepto de observabilidad del físico experimental nunca podrá ser el mismo que el del profano en física, un supuesto que la concepción enunciativa realiza tácitamente. Además, la observabilidad es un concepto que está necesariamente condicionado por el desarrollo histórico de la ciencia: lo que hoy es observable para un físico teórico, apenas lo fue anteriormente para Kepler o Galileo. Por todo ello C. G. Hempel considera innecesario el requisito de un lenguaje observacional en sentido carnapiano como base de interpretación de las teorías científicas. En suma,

the phenomena which a theory is to explain as well as those by reference to which it is tested are usually described in terms which are by no means observational in a narrow intuitive sense, but which have a well-established use in science and are employed by investigators in the field with high intersubjective agreement. I shall say that such terms belong to the antecedently available vocabulary (Hempel 1973: 372),

de modo que la interpretación de los conceptos teóricos no se efectúa con la ayuda de predicados observacionales, sino más bien sobre la base de un lenguaje previamente dispo- 
nible, relativizado por una teoría e intersubjetivamente aceptado por una comunidad científica.

Partiendo de estas consideraciones de C. G. Hempel, W. Stegmüller plantea la necesidad de darle un nuevo sentido a la dicotomía $L_{\delta} L_{t}$ y propone sustituir el lenguaje observacional $L_{o}$, rígido e invariable, por un lenguaje considerado como una variable histórica y pragmática. A este lenguaje, llamado por W. Stegmüller "empiristische Grundsprache", se opondría el lenguaje teórico (1973: 30). La línea de demarcación entre ambos no es rígida, dado que depende de una referencia a las personas, al momento y a las teorías vigentes.

En realidad, este nuevo concepto de 'lenguaje básico empirista' parte de una concepción de la observación científica diametralmente opuesta a la de R. Carnap. Esa concepción, que ha sido defendida por razones distintas por numerosos investigadores en el seno de la teoría de la ciencia (K. R. Popper, T. S. Kuhn, P. Feyerabend, H. Putnam, I. Lakatos, etc.) y cuyos orígenes se remontan a las críticas formuladas por N. R. Hanson en 1958 a la concepción estándar de las teorías, se fundamenta en el postulado cognitivo de la carga teórica de toda observación científica. Según N. R. Hanson la idea de un observador puro y neutral es ficticia, ya que toda observación lleva implícita una 'carga teórica' que la moldea (1977: 99). La observación científica no es inmediata, sino que está determinada por la existencia de conocimientos previos y condicionada conceptualmente. Incluso aparece configurada por el contexto en que se produce e influenciada por el lenguaje utilizado para expresarla. De este modo, dos observadores con conceptos teóricos distintos verán sobre una misma imagen objetos diferentes, puesto que no disponen de una base conceptual común al realizar la observación. Por esa razón el lenguaje observacional no puede reducirse a imágenes o sensaciones, ya que cada uno de sus términos posee un componente teórico que le da sentido y significado (1977: 145).

Aunque W. Stegmüller comparte esta consideración de la observación científica, sigue existiendo un elemento en común entre la concepción originaria de lenguaje observacional y el nuevo concepto pragmático de lenguaje básico empirista. Pues tanto R. Carnap como W. Stegmüller caracterizan lo observacional positivamente merced a que es lo 'completamente comprensible', mientras que lo teórico lo expresan negativamente, por ser lo no observacional, lo no completamente interpretable, lo que carece de plena inteligibilidad. En esa negatividad de la caracterización de lo teórico se constata que ni uno ni otro se han preocupado de analizar con rigor las características auténticamente distintivas de los términos teóricos y la función específica que éstos desempeñan dentro de una teoría.

Pese a las contradicciones que presenta, la concepción clásica de las teorías científicas ha ejercido, y aún ejerce, una notable influencia en los estudios literarios. En numerosas ocasiones configura el fundamento metateórico de determinados modelos de crítica e investigación literarias ${ }^{4}$, por lo que las teorías, conceptos y métodos que esas propuestas desarrollan y aplican se basan, tácita o explícitamente, en los postulados básicos de la visión clásica. Con ello, estos modelos heredan, irremediablemente, las propias contradicciones e

\footnotetext{
${ }^{4}$ Vid. lo expuesto en la nota 2.
} 
insuficiencias de esa visión. A modo de ejemplo que nos permita valorar este fenómeno, en el siguiente apartado nos centraremos en el análisis del modelo conocido como crítica recepcional empírica.

\section{LA CRÍTICA RECEPCIONAL EMPÍRICA Y LA CONCEPCIÓN CLÁSICA DE LAS TEORÍAS CIENTÍFICAS}

Como alternativa al subjetivismo interpretativo de la hermenéutica y como solución a la permanente crisis metodológica de la investigación literaria, en la década de los setenta un grupo de investigadores convienen en la necesidad de elaborar una fundamentación empíri$c a$ de la crítica literaria. El objetivo primordial de dicha fundamentación será el establecimiento de los estudios literarios como una actividad perteneciente a una ciencia socioempírica general de la comunicación, que permita que esos estudios procedan según los criterios de las ciencias empíricas. En especial, es N. Groeben $(1972,1980,1982)$ quien sienta las bases teóricas más significativas para el esbozo de semejante modelo de una crítica literaria recepcional empírica.

A fin de superar la identificación hermenéutica del receptor con el investigador que permita alcanzar unos resultados con validez intersubjetiva, N. Groeben exige que todo proceso interpretativo delimite con claridad la actividad subjetiva y emocional propia de la recepción, esto es, la concretización individual de la obra literaria, frente a la justificación racional y científica de esa recepción, o sea, frente al análisis interpretativo (1972: 168). En su opinión, semejante delimitación sólo podrá ser realmente efectiva si las tareas de recepción e interpretación son atribuidas a distintos sujetos; es decir, si el intérprete, renunciando a 'interpretar' su propia comprensión emocional del texto, establece los datos destinados a servir de fundamento observacional a la interpretación a partir de la comprobación intersubjetiva de las concretizaciones individuales de los receptores. La objetividad en la recopilación de esos datos quedaría garantizada por la utilización de procedimientos metodológicos explícitos e intersubjetivos, propios de las ciencias sociales (por ejemplo, la paráfrasis, el análisis de contenidos, la asociación libre, el diferencial semántico o el 'cloze procedure'). El objeto del conocimiento (las concretizaciones del receptor) y su correspondiente sujeto (el intérprete) quedarían, de este modo, estrictamente diferenciados (Acosta 1989: 285).

Así pues, la concepción de crítica literaria recepcional empírica desarrollada por $\mathrm{N}$. Groeben, al fijar un objeto temático de investigación constituido por la singularidad de las concretizaciones comprensivas de los lectores, pero también en tanto exige la estricta separación del intérprete y del receptor, va a invertir la relación 'subjetivización' de la metodología/objetivización del ámbito de estudio, propia de la hermenéutica clásica, a favor de una objetivización de la metodología interpretativa. La interpretación, entendida como construcción teórica del sentido textual a partir de los múltiples significados individuales atribuidos por los receptores al texto (1980: 133), es decir, como descripción y explicación de los datos recepcionales recopilados intersubjetivamente, no se configurará, a la postre, como una operación propia del receptor, sino, al contrario, como una acción exclusiva del intérprete. El sentido de la obra así construido ya no podrá considerarse como una simple 
especulación subjetiva; antes bien, al estar basado en datos comprobados intersubjetivamente, ofrecería garantías científicas.

El proceder empírico-científico atribuido al crítico literario consiste, en suma, según precisa N. Groeben rigiéndose por las consideraciones metateóricas de la filosofía analítica de la ciencia de corte empírico-positivista, pero también por las desarrolladas por el falsacionismo popperiano, en la formulación o construcción de hipótesis con una gran capacidad explicativa acerca del sentido textual ${ }^{5}$. Estas hipótesis interpretativas, para que en realidad adquieran la condición científica, deben ser contrastables y contrastadas intersubjetivamente, entendiendo dicha contrastación como posibilidad de refutación caso que los datos empíricos, recogidos mediante la observación sistemática y controlada de las concretizaciones textuales, no coincidan con la construcción teórica. Pues, como propuso K. R. Popper $(1935,1965)$, las teorías únicamente podrán ser consideradas empíricas si, en efecto, más que verificadas son falsables merced a un proceso deductivo por los datos observados intersubjetivamente.

Este procedimiento de formulación y comprobación de hipótesis supone una estricta separación entre el nivel propiamente observacional, por un lado, y la interpretación teórica, por otro; un hecho que comporta tanto la clara delimitación del sujeto frente al objeto del conocimiento como, asimismo, la dicotomización del lenguaje científico en un sublenguaje observacional y otro teórico. El establecimiento de la dicotomía 'teóricoíobservacional', por cuanto permite recurrir a datos no-teóricos (1982: 272-273), es considerada por N. Groeben de esencial importancia: sólo así, es decir, si los indicadores empíricos no se presentan relativizados ni se derivan de las hipótesis teóricas establecidas, y los procedimientos de observación y recogida de datos son independientes del observador, se podría garantizar que los enunciados teórico-interpretativos sean efectivamente refutados o, en el mejor de los casos, corroborados de manera imparcial y objetiva por los datos empíricos aportados por las concretizaciones de los receptores.

En definitiva, en un intento por conjugar el procedimiento inductivo de formulación de hipótesis, explicitado por R. Carnap, con el de su comprobación deductiva, conforme al criterio de falsabilidad propuesto por K. R. Popper, N. Groeben presenta dos fórmulas de actuación del crítico empírico en el transcurso del análisis interpretativo. Concretamente, asegura que éste puede optar por determinar el sentido textual mediante su inferencia inductiva a partir de los múltiples datos observacionales aportados por los receptores, o bien, puede contrastar con esos mismos indicadores empíricos una construcción teóricointerpretativa previamente establecida, con el objeto de justificarla o refutarla deductivamente. Los resultados obtenidos por la interpretación literaria, en cuanto construcción teórica del sentido textual, serían considerados adecuados siempre y cuando, tras repetidos intentos, no hubieran sido refutados vía deductiva por los datos empírico-recepcionales

\footnotetext{
${ }^{5}$ Como ejemplo de formulación de hipótesis, N. Groeben ofrece la siguiente construcción teórica referida al aspecto formal del texto: "Der Text T hat in den Dimensionen der Bildstrukturen (Emblem, Topos, Metapher, Allegorie, Symbol etc.) und der Thematologie (Motiv, Charakter, Typus, Fabel, Thema, Idee, Mythos etc.) für die Lesergruppe LG die Bedeutung/den Sinn TB/TS" (1982: 278).
} 
aportados por los lectores; es decir, si tras ser sometidos a prueba por medio de la contrastación con la experiencia, no hubieran podido ser falsados y, en consecuencia, su contenido informativo se manifestara empíricamente consolidado.

A este respecto, N. Groeben expresa su convencimiento de que su modelo sí permite dar solución de modo aceptable a uno de los problemas centrales que se le planteaba al proceder interpretativo de la hermenéutica: la cuestión de la adecuación de la recepción. Tanto más cuanto que los indicadores recepcionales configuran, a la postre, la instancia de la que depende la justificación de las hipótesis interpretativas. Pues, si la adecuación de los resultados del análisis interpretativo está supeditada a la corroboración de éstos mediante la contrastación empírica, la consolidación de su contenido informativo tan sólo podrá ser científicamente efectiva, y se evitará así una 'contradictio in adiecto', a condición de que las instancias falsadoras, o sea, las recepciones textuales, hayan sido asimismo corroboradas, dado que la posibilidad de error también les afecta a ellas. Es concretamente en la búsqueda de una solución apropiada a esta cuestión, es decir, en la dilucidación del proceso de justificación de la recepción adecuada, donde el modelo de Groeben incurre, a nuestro juicio, y precisamente como consecuencia del fundamento metateórico elegido, en una grave incoherencia.

A fin de esclarecer esta problemática, $\mathrm{N}$. Groeben recurre al establecimiento de una relación de legitimación entre lo que él denomina estructura material y objetiva del texto, existente con independencia y anterioridad a toda concretización del significado, y las concretizaciones realizadas por los receptores. El procedimiento metodológico a seguir estriba en un análisis empírico de esa relación, de manera que si se comprueban contradicciones entre la propia configuración material del texto y la estructura conceptual de la concretización ha de catalogarse la recepción como inadecuada. Será, en resumidas cuentas, la compatibilidad con la estructura material del texto lo que determine la adecuación, o más concretamente, como recalca N. Groeben en numerosas ocasiones, la no-inadecuación de la recepción (1980: 142). Pues de acuerdo con el falibilismo popperiano, que al reafirmar el carácter hipotético de las construcciones teóricas estima que el conocimiento de lo que llamamos 'realidad objetiva' no se alcanza mediante una justificación positiva de las teorías, sino únicamente via negationes por la falsación y eliminación de las hipótesis que no superen la contrastación empírica, N. Groeben asume esa relación de asimetría entre la verificabilidad y la falsabilidad de las hipótesis y se sirve de ella para esclarecer la función que la materialidad textual desempeña en el proceso de comprobación de los datos recepcionales: el análisis material del texto no puede ratificar o confirmar positivamente una recepción, pero sí en cambio, ex negativo, puede refutarla y descartarla, o sea, falsarla definitivamente.

Se trate de la adecuación, o bien, de la no-inadecuación de la recepción, lo cierto es que esta diferenciación conceptual, o si se quiere metódica, en nada altera el hecho de que es en la posibilidad de constatación objetiva de la materialidad textual y en la supuesta relación de legitimación entre estructura material y sentido, donde el procedimiento metodológico de comprobación de hipótesis recepcionales, explicitado por N. Groeben, encuentra su fundamento. En efecto, la estructura material del texto tendrá que ser la que en última ins- 
tancia decida sobre el grado de aceptabilidad o verisimilitud de los significados y sentidos que se le han atribuido. Y ello va a suponer, a la postre, que sean los datos específicamente textuales, y no los aportados por el lector, el factor que determine unilateralmente la licitud de los resultados recepcionales.

En rigor, N. Groeben no logra desembarazarse por completo de los postulados sustancialistas que había intentado superar y llega, en definitiva, a trasladar a otro nivel, concretamente al ámbito de la recepción, el problema axial de la hermenéutica clásica, esto es, la adecuada constatación del sentido fijo e invariable que supuestamente le es inherente a la obra literaria. Por ello, y al sustentarse este modelo empírico-literario en la posibilidad de un conocimiento objetivo de la realidad textual, su propuesta no puede más que derivar en la asunción, cuando menos de manera implícita, del concepto ontológico e inmanente del texto propio de la hermenéutica, que había intentado eludir. Pues cómo podría ejercer, efectivamente, la materialidad textual de correctivo, o bien, de medida imparcial de comprobación de las concretizaciones del significado, si no se presumiera que éste ya está implantado en el texto, de modo fijo e invariable, previamente a la actuación del lector. Únicamente bajo este supuesto se podría admitir que la materialidad textual es susceptible de legitimar el significado que se le ha otorgado.

Estimamos, en suma, que el origen de las deficiencias y contradicciones del modelo propuesto por N. Groeben radican en las propias insuficiencias del fundamento metateórico elegido. Pues, como ha demostrado con claridad la propia teoría de la ciencia, los criterios teórico-científicos del empirismo positivista de $\mathrm{R}$. Carnap, pero también los del racionalismo crítico de K. R. Popper, contradicen el proceder real de la ciencia, al no tener en cuenta que los indicadores o datos observacionales que otorgan legitimidad o ilegitimidad a las teorías no son realmente independientes ni están libres de relatividad teórica. Estos indicadores no tienen validez ni son adecuados o inadecuados en términos absolutos, sino sólo con relación al sistema teórico o modelo de realidad al que en última instancia pertenecen. En consecuencia, la dependencia teórica de los datos recepcionales muestra el desacierto que supone legitimar la actividad recepcional recurriendo a la materialidad 'objetiva' del texto. Una adecuada fundamentación metateórica de la investigación literaria debería sustentarse, en ese caso, en una aclaración precisa de la función que los conceptos y construcciones teóricas desempeñan en toda actividad cognoscitiva y científica.

\section{PARADIGMAS Y REVOLUCIONES CIENTÍFICAS}

Es a partir de la publicación en 1962 en la International Encyclopedia of Unified Scien$c e$, uno de cuyos editores es $\mathrm{R}$. Carnap, de la obra The structure of scientific revolutions del físico teórico e historiador de la ciencia T. S. Kuhn, cuando se avanza notablemente en la aclaración de la función que el ámbito teórico desempeña en el proceder real del científico y se demuestra la imposibilidad de separar estrictamente el nivel observacional del teórico. La originalidad del modelo desarrollado por T. S. Kuhn estriba en la introduccción de criterios psicológicos y sociológicos como determinantes de la práctica real del científico, un planteamiento que fue prematuramente desdeñado por la teoría de la ciencia. 
Al igual que N. R. Hanson, T. S. Kuhn no admite ni la inmediatez ni la neutralidad de las percepciones. Para él no existe una base empírica común a todos los científicos, ni por supuesto un lenguaje observacional objetivo, existente con anterioridad a toda construcción teórica. Cada teoría paradigmática determina globalmente la visión del científico, dando lugar a un concepto de ciencia propio con sus correspondientes métodos de investigación, campo de estudio, lenguaje, etc. Como consecuencia de ello, el progreso de la ciencia no se produce de forma continuada y acumulativa, sino, muy al contrario, mediante crisis y rupturas revolucionarias que suponen cambios radicales en las concepciones científicas. Según T. S. Kuhn, el avance de la ciencia es un proceso que se efectúa en tres fases fundamentales: ciencia normal, crisis y revolución.

La ciencia normal es aquella forma de investigación realizada durante cierto tiempo por una comunidad científica en el marco conceptual de un paradigma. Un paradigma es un 'modelo' o 'patrón' aceptado por los científicos en un determinado momento, que establece qué leyes y teorías hay que considerar válidas, así como qué problemas y métodos de solución son significativos. Un paradigma está compuesto, por un lado, por teorías y sus aplicaciones y, por otro, por normas y métodos de procedimiento compartidos por una comunidad (Kuhn 1962: cap. V). Una vez aceptado el paradigma, éste determina toda la actividad y todas las concepciones del científico, desde su forma de trabajar hasta el modo en que observa los fenómenos, ya que éstos no existen al margen del paradigma, sino que siempre son constituidos por él. En la fase de ciencia normal reina el consenso en el seno de la comunidad científica merced a un compromiso tácito acerca de los temas de estudio, objetivos de la investigación, métodos, modelos de soluciones posibles, conocimientos estables, etc. La actividad científica normal no persigue la realización de grandes descubrimientos o efectuar inesperadas predicciones. Más bien, el científico intenta precisar y articular cada vez con mayor exactitud el paradigma con el propósito de 'obligar' a la naturaleza a que encaje dentro de los moldes establecidos por él, pero nunca tratará de refutarlo o falsearlo en un sentido popperiano (Kuhn 1962: 38). Los únicos problemas posibles en esta fase de ciencia normal son los derivados de la aceptación del paradigma operativo, unos problemas cuya solución se vislumbra en su marco. A la tentativa de resolver estos problemas, llamados por T. S. Kuhn puzzles o enigmas, la ciencia normal consagra prácticamente todo su tiempo y esfuerzos, garantizando el desarrollo científico en la medida en que logra sucesivas soluciones eficaces. En esta etapa, el progreso científico será de carácter acumulativo y restringido, constituyendo el paradigma su propia limitación, al tener que realizarse el incremento de conocimientos dentro de los márgenes impuestos por él y en una dirección previamente establecida. En cualquier caso, en todo estadio de investigación científica normal surgirán repetidamente numerosos fenómenos nuevos e inesperados, que no serán explicables en el marco del paradigma en cuestión, y que incluso lo contradirán. Estos fenómenos dejarán de considerarse enigmas solucionables para convertirse en anomalías. La aparición de anomalías no significará nunca la refutación del paradigma. A lo sumo, el científico intentará corregir el paradigma y adaptarlo a las nuevas circunstancias; con frecuencia las ignorará con la esperanza de que, eventualmente, se muestren irrelevantes. T. S. Kuhn rechaza por ello equiparar las instancias anómalas con instancias falsadoras, como propugna K. R. Popper, y niega incluso la existencia de éstas últimas enfrentándose a la 
postura del filósofo austríaco ${ }^{6}$. Pues, "wenn jede einzelne Nichtübereinstimmung ein Grund für die Ablehnung einer Theorie wäre, müßten alle Theorien allzeit abgelehnt werden" (1962: 157). La incapacidad de encontrar una solución a las anomalías llega a desacreditar, en esta fase, no a la teoría en sí, sino sólo al hombre de la ciencia que hace uso de ella (1962: 93).

Con estas consideraciones, T. S. Kuhn no niega la posibilidad de que una teoría pueda ser rechazada y que la experiencia y los experimentos desempeñen en este proceso un papel determinante. Sin embargo, cree que el abandono de las teorías únicamente sucede cuando un paradigma desplaza a otro en el transcurso de una revolución científica. Hasta no disponer de una nueva teoría el científico mantendrá la antigua, dado que sin la herramienta conceptual de una teoría el científico no podrá trabajar. La ciencia se verá obligada a renunciar a un paradigma en el caso que los fenómenos de la naturaleza se resistan a someterse cada vez con más virulencia y en mayor cantidad al modelo paradigmático en cuestión, es decir, si las anomalías aumentan en número e importancia, extendiéndose por ámbitos cada vez más amplios, y el paradigma se muestra incapaz de asimilarlas. La toma de conciencia de estos hechos conducirá a la ciencia normal a una situación de crisis, una nueva fase en el desarrollo científico, llamada por T. S. Kuhn también 'ciencia extraordinaria', que acabará dando lugar a una revolución científica y a la aceptación de un nuevo paradigma. En esta situación de crisis, la incapacidad del paradigma para asimilar las múltiples anomalías ya no se considera un fracaso del científico, sino de la teoría (Kuhn 1970: 7). Síntomas de esta fase son la proliferación de teorías, el recurso a los debates sobre los fundamentos teóricos, la disposición a ensayarlo todo, incertidumbre, etc.

Esta situación de crisis finalizará cuando aparezca un nuevo paradigma capaz de ganarse la confianza de un número cada vez mayor de investigadores dispuestos a constituir una comunidad científica y a iniciar una nueva fase de ciencia normal. Es en este momento cuando se produce la sustitución del paradigma en crisis por el nuevo, originándose una revolución científica. Sin embargo, la nueva teoría que ha sido aceptada como paradigma no es más 'verdadera' que la antigua. Es simplemente más apropiada y útil para la solución de los problemas que se le han planteado a la actividad científica: la nueva teoría debe resolver más satisfactoriamente que las teorías competidoras una serie de problemas considerados generalmente graves y que se supone fueron causantes de la crisis; además ha de permitir la resolución de problemas ya explicados por los paradigmas anteriores (1962: 181). En cambio, no necesita explicar todos los hechos que se puedan confrontar con ella 0 lograr resultados satisfactorios en un considerable número de cuestiones; ni siquiera se exige que tenga un éxito completo en la resolución de un problema determinado (1962: 32 y 37). "Der Erfolg eines Paradigmas <...> ist am Anfang weitgehend eine Verheißung von Erfolg, die in ausgesuchten und noch unvollständigen Beispielen liegt" (1962: 37-38). En definitiva, su elección obedece en un principio a razones de pura pragmática. Sólo su desarrollo y precisión posterior garantizará la aceptación duradera del nuevo paradigma y el inicio de una nueva fase de ciencia normal.

\footnotetext{
${ }^{6}$ Sobre la controversia entre Popper y Kuhn, cfr. Maldonado Alemán (1981).
} 
Las revoluciones científicas suponen un cambio radical en el modo de ver el mundo y en las concepciones de los científicos. Se modifican el objeto y los métodos de investigación, así como la aplicación de los conocimientos ya existentes. Los hechos conocidos anteriormente se vuelven a definir y el campo de estudio se reconstruye a partir de nuevos fundamentos. El concepto mismo de ciencia y, en parte, las generalizaciones teóricas más elementales aparecen completamente transformados a la luz del nuevo paradigma. Empiezan a observarse nuevos fenómenos hasta entonces desconocidos, al investigarse aspectos anteriormente ignorados, o bien, al utilizarse un instrumental de investigación distinto (1962: 123).

\section{LA CONCEPCIÓN ESTRUCTURAL DE LAS TEORÍAS CIENTÍFICAS}

A pesar de la claridad y convencimiento con que fueron expuestas, estas significativas ideas de T. S. Kuhn no fueron aceptadas inmediatamente e incluso pasaron inadvertidas durante años. Esta situación cambió radicalmente con la publicación en 1971 de la obra de J. D. Sneed The logical structure of mathematical physics y su posterior aplicación a las ideas de T. S. Kuhn realizada por W. Stegmüller $(1973,1975,1979,1980)$. La obra de J. D. Sneed vino a complementar y a aclarar las propuestas kuhnianas, dándoles un decisivo y fundamental impulso que posibilitó poco después su definitiva difusión?

J. D. Sneed logra precisar positivamente y con rigor la función específica que los conceptos teóricos desempeñan en una teoría empírico-científica. Para él, la teoricidad de un término, y también su no teoricidad, siempre es relativa a una teoría determinada, de modo que todo término teórico, o no-teórico, tomado por sí sólo carece de sentido. Estos términos reciben significado únicamente mediante una interpretación realizada en el marco de una teoría. De ahí que un mismo concepto teórico pueda tener significados distintos en orden a si ha sido interpretado en el contexto de una teoría u otra. Incluso puede ocurrir que un mismo término sea teórico con respecto a una teoría, y no-teórico con relación a otra. $\mathrm{O}$ también que los componentes no-teóricos de una teoría sean componentes teóricos de otra teoría. Los términos no-teóricos de una teoría ocupan, sin embargo, una posición jerárquicamente inferior respecto a los términos teóricos de la misma teoría. Con estas consideraciones J. D. Sneed llega a un nuevo concepto relativizado de teoricidad, en el que el predicado ya no es ' $x$ es un término teórico', sino ' $x$ es un término $t$-teórico' (Stegmüller 1973: 33).

La introducción de este concepto de teoricidad supone el abandono de la dicotomización carnapiana, al ser rechazada la existencia de dos sublenguajes $L_{o}$ y $L_{t}$, disjuntos y fijos, y dada la posibilidad de aceptar un término como teórico en relación con una teoría determinada, pero no-teórico con respecto a otra. A diferencia de la concepción clásica, que caracteriza lo no-teórico positivamente (lo 'observable', lo 'plenamente comprensible') e

\footnotetext{
${ }^{7}$ No es nuestra intención explicar aquí en detalle la visión estructural o no proposicional de las teorías científicas. Para un análisis pormenorizado, cfr. Sneed (1971, 1976); Stegmüller (1973, 1979, 1980); Moulines (1982); Finke (1982); Balzer/ Sneed (1983); Rivadulla Rodríguez (1986: 241-277); Balzer/ Moulines/ Sneed (1987); Echeverría (1989: 149198).
} 
introduce lo teórico negativamente (lo 'no-observacional', lo 'no plenamente comprensible'), la concepción de J. D. Sneed procede de forma exactamente inversa: lo teórico se determina positivamente y lo no-teórico negativamente por no satisfacer el criterio de $t$ teoricidad. Además, en el nuevo criterio no se presentan las desventajas mencionadas del lenguaje observacional, pues ya no se exige que los términos no-t-teóricos deban ser caracterizados̀ positivamente como observacionales. 'No-t-teórico' significa exclusivamente que las entidades correspondientes son no-teóricas respecto a la teoría $T$; en relación con otra teoría $T$ ' se configuran, en cambio, como entidades teóricas. Es decir, los términos no-tteóricos siempre se presentan relativizados por alguna teoría, con lo que en el nuevo criterio de teoricidad propuesto por J. D. Sneed se supera con claridad la dicotomía carnapiana 'teórico/observacional', siendo ésta sustituida por la oposición entre términos $t$-teóricos y términos no-t-teóricos. Por otra parte, en este concepto de teoricidad desaparece la problemática de las condiciones de adecuación para las reglas de correspondencia, ya que éstas son innecesarias al no tomarse como punto de partida lo observable.

En esta visión no proposicional ('non-statement view'), también conocida como concepción conceptual ('Begriffskonzeption') o estructural ('structuralist view') de las teorías científicas ${ }^{8}$, las teorías son consideradas bajo un aspecto funcional y otro estructural. Desde una perspectiva funcional las teorías científicas son instrumentos para la solución de los problemas que se le plantean a la actividad investigadora. Una teoría tiene la función de satisfacer la necesidad de explicación de un grupo de científicos respecto a una sección de la realidad. Para que un problema tenga un carácter ciertamente científico, es necesario que se plantee dentro de un marco térico preciso. En consecuencia, el ámbito de aplicación de las teorías no está constituido por hechos, sino por problemas derivados de la actividad científica. Desde una perspectiva estructural las teorías científicas son constructos, es decir, en ningún caso son productos dados por el mundo 'real', constituidos por un componente formal, que es la estructura lógica de la teoría, y un componente empírico, compuesto por la especificación del ámbito de la realidad sobre el que se pretende aplicar la estructura lógica de la teoría: "A scientific theory is a conceptual structure that can generate a variety of empirical claims about a loosely specified, but not completely unspecified, range of applications" (Sneed: 1976: 120). Para que la teoría cumpla efectivamente con su función específica, su estructura lógica ha de ser construida de tal forma que permita interpretar esa sección de la realidad, o sea, sobre ese ámbito de aplicación el componente lógico-formal de una teoría debe permitir la obtención de descripciones y explicaciones empíricas precisas. No es, por consiguiente, la estructura la que determina la función de una teoría, sino al revés: de la razón práctica de la teoría dependerá su razón teórica (Finke 1982: 71).

\footnotetext{
${ }^{8}$ Sneed demuestra su concepción de las teorías científicas en el marco de la física matemática. Balzer (1982) y Diederich (1981) utilizan esa concepción para reconstruir teorías económicas y psicológicas. Göttner/ Jakobs (1978), Barsch (1981), Balzer/ Göttner (1983), Hauptmeier/ Schmidt (1985) y, especialmente, Finke (1981, 1982) han adaptado y aplicado la concepción de Sneed a la ciencia literaria.
} 


\section{LA CONCEPCIÓN ESTRUCTURAL DE LAS TEORÍAS CIENTÍFICAS COMO FUNDAMENTO METATEÓRICO DE LA INVESTIGACIÓN LITERARIA}

En términos generales, en la concepción estructural una teoría empírico-científica es considerada como el significado de un predicado. Por un predicado la lógica moderna entiende una función proposicional del tipo ' $F(x)$ ' o, expresado lingüísticamente, ' $x$ es $F$ '. Dado que el significado de un predicado es un concepto, se pueden concebir las teorías empíricas igualmente como conceptos. Un predicado concreto como ' $x$ es un poema' $o$ ' $x$ es una acción literaria de recepción' se puede completar con una proposición especificadora de los objetos o fenómenos reales que estén comprendidos dentro del concepto expresado por dicho predicado, es decir, podemos asignar a $x$ nombres concretos de objetos reales. De este modo, en esta concepción no proposicional una teoría empírica está compuesta por una ley fundamental, que es el significado de un predicado, de la que se supone que encaja en una determinada sección de la realidad. Con la ayuda del componente lógico de la teoría se pueden establecer aserciones empíricas concretas sobre esa sección de la realidad, afirmando que ese ámbito de la realidad satisface la estructura lógica de la teoría. Esa afirmación se puede construir con una predicación del tipo ' $x$ es un $S$ ', donde $x$ designa una entidad y $S$ expresa la estructura lógica de la teoría. $S$ caracteriza la estructura lógica básica de la teoría en el sentido que permite determinar el conjunto de entidades de una sección de la realidad a las que la teoría puede ser aplicada. Por tal motivo esa estructura puede ser concebida como la ley fundamental de la teoría. Sin la formulación de esa ley fundamental no pueden construirse en la ciencia teorías empíricas (Finke 1982: 144-146, 153 y 156; Hauptmeier/ Schmidt 1985: 39-40).

Para construir una teoría empírica es necesario, pues, establecer un predicado fundamental. A tal efecto, se ha de elegir primeramente una expresión lingüística para la designación del concepto que expresa el predicado; en segundo lugar, se ha de señalar el significado de ese concepto, esto es, su estructura lógica; y, en tercer lugar, se ha de determinar el dominio empírico al que se refiere el concepto, es decir, el ámbito de aplicación de la teoría. El primer paso en la construcción de una teoría no suele ofrecer ninguna dificultad, ya que se trata de asignar un nombre a un concepto. El segundo y el tercer paso son, en cambio, más problemáticos. Aquí se trata de ofrecer tanto la definición intensional del concepto denotado por el predicado, es decir, la explicación de la estructura lógica $S$ de la teoría, como su definición extensional, esto es, la especificación de la sección de la realidad sobre la que se pretende aplicar la teoría (Finke 1982: 144 y ss.; Hauptmeier/ Schmidt 1985: 40).

Toda teoría científica comienza a desarrollarse para ser aplicada al estudio sistemático de un determinado dominio empírico, o sea, a fin de dar una solución satisfactoria a ciertos problemas científicos. Si seguimos los conceptos básicos de la Teoría Empírica de la Literatura, desarrollada por S. J. Schmidt y el grupo de investigación NIKOL, el objeto de

\footnotetext{
${ }^{9}$ En lo que concierne a la caracterización de las teorías empíricas, J. D. Sneed parte de la convicción de que una teoría científica puede ser axiomatizada de forma precisa sin que haga falta recurrir a lenguajes formales. Por esa razón opta por una axiomatización informal, eligiendo la técnica del predicado conjuntista propuesta por P. Suppes, y desestima con ello, explícitamente, el tipo de axiomatización propuesto por la concepción clásica que reduce las teorías científicas a cálculos al modo de la metamatemática.
} 
estudio de la investigación literaria lo formarían todas aquellas acciones de producción, mediación, recepción y elaboración (en forma de comentarios, críticas, interpretaciones, traducciones, etc.) que componen el sistema social de la literatura. Este sistema constituiría, en nuestro caso, el ámbito global de aplicación propuesto $I$ ("intendierter Anwendungsbereich") de la teoría, que forma su componente empírico, es decir, es la sección de la realidad que se pretende describir y explicar con la ayuda de la teoría. Dada la amplitud y complejidad del sistema de la literatura, el investigador seleccionará para su estudio una u otra de las secciones que componen ese dominio, e incluso investigará en detalle cuestiones muy específicas de cada sección. A esas cuestiones concretas o fenómenos específicos que necesitan de una explicación se les llama modelos potenciales parciales $\left(M_{p p}\right)$ de la teoría (Finke 1982: 155). En el caso, por ejemplo, de una teoría de la recepción literaria, los $M_{p p}$ son las acciones concretas de lectura o audición de un texto que es considerado literario. Esos modelos son descritos mediante un lenguaje no especializado, o bien, utilizando expresiones teórico-literarias tradicionales. En semejantes descripciones el investigador usa los componentes o términos no-teóricos de la teoría, esto es, los componentes que en relación con la teoría en cuestión son considerados no-teóricos (componentes no-t-teóricos). Los $M_{p p}$ comprenden, de esta forma, todas las descripciones no-t-teóricas de un conjunto de fenómenos. Esos modelos así descritos son exactamente modelos potenciales parciales de la teoría, o sea, un producto de los recursos conceptuales utilizados en su descripción, por lo que la descripción efectuada no se refiere a una 'realidad' considerada independiente de cualquier teoría (Stegmüller 1973: 233). De hecho, los términos usados en la descripción son teóricos con relación a alguna otra teoría.

Una vez establecida la descripción de los $M_{p p}$, el siguiente paso consiste en la explicación de esos modelos con la ayuda de los componentes o términos teóricos de la teoría. Aquellos fenómenos a los que se refiere el investigador utilizando conjuntamente los componentes $t$-teóricos y los componentes no-t-teóricos son los llamados modelos potenciales $\left(M_{p}\right)$ de la teoría (Finke 1982: 155). Los modelos potenciales son exactamente aquellas entidades a las que, a la luz de la teoría en cuestión, se podría preguntar razonablemente si ' $x$ es un $S$ ', es decir, si esas entidades cumplen o no la ley fundamental de la teoría, o si los axiomas de la teoría son aplicables a ese ámbito. O sea, además de los conceptos no-tteóricos, el investigador se verá obligado a introducir los conceptos $t$-teóricos de la teoría, para que así pueda formular unas hipótesis que le permitan explicar el fenómeno en cuestión. En el caso de una teoría de la recepción literaria, los $M_{p}$ son todas aquellas acciones realizadas por un lector u oyente que se pueden describir con los conceptos $t$-teóricos y no$t$-teóricos de la teoría. Esos conceptos $t$-teóricos podrían ser 'receptor literario', 'sistemas de presuposiciones literarias del receptor literario', 'situación literaria de recepción', 'estrategia literaria de recepción', 'acción literaria de recepción', 'resultado de la recepción literaria', etc. (Schmidt 1980: 267). Los $M_{p}$ de una teoría pueden ser considerados como una teorización de los $M_{p p}$ de la misma teoría. Por otro lado, de los $M_{p}$ pueden obtenerse los $M_{p p}$ suprimiendo los componentes $t$-teóricos de la teoría tras aplicar la función de reducción $r$.

Las entidades de los $M_{p}$ que efectivamente cumplen el predicado 'es un $S$ ', o sea, la ley fundamental de la teoría en cuestión, son los llamados modelos $(M)$ de la teoría. Los $M$ de 
una teoría constituyen, por tanto, todos los fenómenos o elementos pertenecientes a su ámbito de aplicación I que han sido descritos y explicados, o sea, interpretados con la ayuda de dicha teoría (Finke 1982: 156). La ley fundamental, en el caso de una teoría de la recepción literaria, puede describirse lingüísticamente con la expresión ' $R$ actúa receptivamente en la comunicación literaria' (Schmidt 1980: 267). De acuerdo con esa ley, los $M$ de la teoría de la recepción literaria estarán constituidos por todas aquellas acciones que con la ayuda de los componentes $t$-teóricos de la teoría puedan ser efectivamente identificadas como acciones literarias de recepción. Como leyes típicas de $M$ podrían ser consideradas en ese caso las convenciones estética y de polivalencia ${ }^{10}$. La existencia de esos modelos es lo que permite afirmar que la teoría posee un contenido empírico. Es decir, el carácter empírico de la teoría no depende de los conceptos que en ella aparezcan, sino exclusivamente de la posibilidad de que, utilizando el dispositivo conceptual de la teoría, se pueda decidir si una entidad determinada es un modelo de la estructura lógica de la teoría (Finke 1982: 154).

En suma, una teoría científica, desde la perspectiva de la concepción conceptual, puede ser representada por el par $\langle K, I\rangle$, donde $K$ designa el núcleo estructural o formal de la misma ('formaler Kern'), es decir, el componente lógico de la teoría que está constituido por los $M_{p p}$, los $M_{p}$ y los $M$, construidos a partir de la observación de un determinado dominio empírico, y por la función $r$; e $I$ indica el componente empírico de la teoría, es decir, su ámbito de aplicación o de interpretación previsto. Ahora bien, para que las interpretaciones de $I$ estén relacionadas y no sean totalmente independientes entre sí, es necesario introducir en el núcleo $K$ un conjunto de restricciones $C$ (constraints) que se apliquen a los componentes teóricos de la teoría, o sea, a los $M_{p}$ (Finke 1982: 153 y 156; Sneed 1976: 122 y ss.; Balzer/ Sneed 1983: 121). Estas restricciones se pueden concebir como condiciones generales de interpretación de $I$, que establecen ciertas relaciones de dependencia entre las distintas aplicaciones de los elementos teóricos. Las restricciones a las que son sometidos los $M_{p}$ pueden consistir, por ejemplo, en que los valores de una función teórica no puedan fijarse en una aplicación sin tener en cuenta los valores de la misma función teórica en otras aplicaciones de la teoría. En una teoría de la recepción literaria se podría establecer, por ejemplo, la restricción general de que las acciones de recepción sean efectuadas intencionalmente con 'textos literarios', y que los textos que se le presenten a un receptor o a distintos receptores al mismo tiempo o en momentos diferentes sean, con independencia de la acción de recepción, materialmente idénticos (Hauptmeier/ Schmidt 1985: 97). De esta manera, la estructura lógica de una teoría o núcleo $K$ quedaría configurada definitivamente por el quíntuplo ordenado $\left\langle M, M_{p}, M_{p p}, C, r\right\rangle$, siendo estos componentes los elementos que definen intensionalmente el concepto expresado por el predicado de dicha teoría.

\footnotetext{
${ }^{10}$ Según la Teoría Empírica de la Literatura, la convención estética establece que quien quiera participar en la comunicación literaria debe estar dispuesto a admitir y a orientarse hacia normas, valores y reglas de significación distintos a los establecidos por las reglas de verdad o de utilidad práctica que son propias del modelo de realidad de su mundo de experiencia social y que rigen la comunicación no literaria. Por su parte, la convención de polivalencia establece que los participantes realicen la comunicación estética efectivamente de modo polivalente, evitando la univocidad propia de la comunicación no literaria. Cfr. Schmidt (1980: 100 y ss.).
} 
Las teorías empíricas son construcciones conceptuales muy complejas que, por lo general, admiten múltiples aplicaciones. Para determinadas aplicaciones muy concretas, el investigador no podrá recurrir a la ley fundamental de la teoría, sino que necesitará leyes especiales. Para el caso concreto de la literatura, además de una teoría general que le permita estructurar el complejo sistema social de la literatura, necesitará unas teorías particulares para la descripción y explicación de las distintas acciones literarias de producción, mediación, recepción y elaboración. Estas teorías elementales serían elementos teóricos de la teoría general de la literatura. Un elemento teórico, por tanto, es la mínima unidad constitutiva de una teoría, con cuya ayuda se pueden realizar afirmaciones empíricas. Hay teorías empíricas, como la de la geometría física, que están formadas únicamente por un solo elemento teórico. Sin embargo, por regla general, una teoría está compuesta por un tejido de diferentes elementos teóricos. Sería necesario, consiguientemente, precisar el concepto de 'término teórico' y determinar las relaciones que se pueden establecer entre ellos para constituir una teoría.

Los dos componentes estructurales más importantes de una teoría, el teórico y el noteórico, se pueden diferenciar explícitamente con la introducción del concepto ' $m+k$-matriz de un elemento teórico', que distingue dos series limitadas de componentes $n$ y $t$ con una cuantificación respectiva $m$ y $k$. Esta matriz describe el conjunto de elementos que se suponen forman la estructura lógica del elemento teórico. J. D. Sneed define la matriz de un elemento teórico de la siguiente manera (1976: 123):

D 1 X es una m+k-matriz de un elemento teórico si y sólo si

(1) $X \in M$

(2) $\mathrm{m}$ y $\mathrm{k}$ son números enteros positivos: $0<\mathrm{m}, 0 \leq \mathrm{k}$;

(3) para todo $x \in X$ hay $n_{1}, \ldots, n_{m}, t_{1}, \ldots, t_{k} \in M$, de modo que $x=\left\langle n_{1}, \ldots, n_{m}, t_{1}, \ldots, t_{k}\right\rangle$.

En esta definición se especifica que $x \in X$ es un $m+k$-tuplo (esto es, un conjunto ordenado) de conjuntos, relaciones y funciones, formado por componentes no-t-teóricos y componentes $t$-teóricos. (1) expresa que $X$ es un conjunto no vacío. (2) señala una cantidad de componentes $n$ (componentes no-t-teóricos) y de componentes $t$ (componentes $t$-teóricos). Finalmente (3) expone que $x \in X$ es una construcción ordenada de $n$ y $t$, el llamado $m+k$ tuplo. Según (2), el número de los componentes $n$ es siempre mayor que $0(0<m)$, lo que hace posible un primer acercamiento del investigador al ámbito de aplicación o de interpretación propuesto $I$ de la teoría, es decir, la configuración de $M_{p p}$. Asimismo, según (2), el número de los componentes $t$ puede tomar, no obstante, el valor $0(0 \leq k)$, por lo que con esta matriz se tienen en consideración aquellos elementos de la teoría que en un momento determinado de su elaboración no poseen componentes $t$-teóricos. Cuando $0<k$, los modelos $M_{p}$ cumplen la matriz, dado que en esos modelos aparecen componentes $t$-teóricos y componentes no-t-teóricos; si $0=k$, entonces son los modelos $M_{p p}$ los que cumplen la matriz (Hauptmeier/ Schmidt 1985: 48; Finke 1982: 152; Balzer/ Sneed 1983: 121).

$\mathrm{El}$ aparato conceptual fundamental y estable de un elemento teórico está representado matemáticamente por la estructura llamada núcleo $K$ de un elemento teórico. Este núcleo 
constituye el componente lógico del elemento teórico, que los científicos utilizan para realizar descripciones y explicaciones empíricas del ámbito de aplicación $I$ de dicho elemento teórico. La misma denominación de 'núcleo' alude a la importancia fundamental de este componente, imprescindible en cualquier teoría, y al hecho de que los científicos mantienen el núcleo de una teoría, aun cuando ésta se muestre incapaz de dar solución a las anomalías que surjan en la investigación empírica. Precisamente la introducción de este concepto de 'núcleo' va a permitir que las propuestas no formalizadas de T. S. Kuhn sean definidas con precisión. Siguiendo a W. Balzer y J. D. Sneed, el concepto de 'núcleo de un elemento teórico' se puede definir formalmente de la siguiente manera (1983: 121):

D 2 X es un núcleo de un elemento teórico si y sólo si hay Mp, Mpp, r, M, C, m y k, de modo que:

(1) $\mathrm{X}=\langle\mathrm{Mp}, \mathrm{Mpp}, \mathrm{r}, \mathrm{M}, \mathrm{C}\rangle$

(2) Mp es una $\mathrm{m}+\mathrm{k}$-matriz de un elemento teórico

(3) $\mathrm{Mpp}:=\{\langle\mathrm{n} 1, \ldots, \mathrm{nm}\rangle /$ hay $\mathrm{t} 1, \ldots, \mathrm{tk}$, de modo que $\langle\mathrm{n} 1, \ldots, \mathrm{nm}, \mathrm{t} 1, \ldots, \mathrm{tk}\rangle \in \mathrm{Mp}\}$

(4) $\mathrm{r}: \mathrm{Mp} \rightarrow$ Mpp está definida por $\mathrm{r}(\mathrm{n} 1, \ldots, \mathrm{nm}, \mathrm{t} 1, \ldots, \mathrm{tk}):=\langle\mathrm{n} 1, \ldots, \mathrm{nm}\rangle$

(5) $\mathrm{M} \subseteq \mathrm{Mp}$

(6) C es una restricción para $M_{p}$.

En esta definición, (1) expone los componentes estructurales del núcleo de un elemento teórico, que ya hemos explicado. (2) incluye en este núcleo la $m+k$-matriz de un elemento teórico mediante los $M_{p}$ del mismo, teniendo en cuenta que en esos modelos parciales ya aparecen unidos en forma de descripciones y explicaciones los componentes $t$-teóricos y los componentes no-t-teóricos del elemento teórico. (3) señala que existen componentes $t$ teóricos $\left(t_{l}, \ldots, t_{k}\right)$ que pueden ser aplicados a los $M_{p p}$ del elemento teórico y que permiten pasar ciertas entidades del conjunto de $\operatorname{los} M_{p p}$ al conjunto de los $M_{p}$. La entidad que satisfaga tanto los componentes $t$-teóricos como los componentes no-t-teóricos $\left(n_{l}, \ldots, n_{m}\right)$ es un elemento del conjunto de los modelos potenciales del elemento teórico. (4) expresa que la función $r$ suprime de los $M_{p}$ los componentes $t$-teóricos, obteniéndose el conjunto de los $M_{p p}$ compuesto por los componentes no- $t$-teóricos del aparato conceptual. (5) indica la igualdad o inclusión del conjunto de los $M$ en el conjunto de los $M_{p}$ del elemento teórico. Los $M$ estarían compuestos por los elementos de los $M_{p}$ que cumplen la ley fundamental del elemento teórico. Finalmente, (6) especifica el concepto y el ámbito de aplicación del conjunto de restricciones $C$ (Finke 1982: 154; Chico Rico 1987: 56-57).

Una vez aclarados los componentes estructurales del núcleo de un elemento teórico, se puede definir formalmente el concepto de elemento teórico (Balzer/ Sneed 1983: 122):

D $3 \mathrm{X}$ es un elemento teórico si y sólo si hay $\mathrm{K} \in \mathrm{I}$, de modo que

(1) $\mathrm{X}=\langle\mathrm{K}, \mathrm{I}\rangle$

(2) $\mathrm{K}=\langle\mathrm{Mp}, \mathrm{Mpp}, \mathrm{r}, \mathrm{M}, \mathrm{C}\rangle$ es un núcleo de un elemento teórico

(3) $I \subseteq M p p$. 
Según (1), un elemento teórico está compuesto por un núcleo formal $K$, que constituye el componente lógico, y por un ámbito de aplicación propuesto $I$, que es su componente empírico. (2) señala la estructura lógica del núcleo que ya ha sido definida en D2. (3) impone la condición de que todos los elementos de $I$ tengan la misma estructura que el componente no teórico de $K$, esto es, que formen parte del conjunto de los $M_{p p}$.

Del núcleo $K$ de un elemento teórico se puede elegir una determinada clase de conjuntos parciales de $M_{p p}$. A esta clase se denomina $A(K)$ y designa el contenido empírico de $K$. La regla de elección es la siguiente: Se considera que un conjunto de $M_{p p}$ se encuentra en $A(K)$, si a cada elemento de ese conjunto se le pueden añadir componentes teóricos, de modo que se establezcan modelos $M$ del elemento teórico y todo el ámbito de las funciones teóricas añadidas cumplen el conjunto de restricciones $C$. La pertenencia de un determinado conjunto de $M_{p p}$ a la clase $A(K)$ significa, precisamente, que la teoría ha sido aplicada con éxito a esos $M_{p p}$. Por consiguiente, con un elemento teórico se puede establecer una afirmación empírica tal como lo especifica la siguiente definición (Balzer/ Sneed 1983: 122):

D $4 \mathrm{Si}\langle\mathrm{K}, \mathrm{I}\rangle$ es un elemento teórico, entonces

$I \in A(K)$

es la afirmación empírica de $\mathrm{K}$.

La afirmación empírica consiste en aseverar que $I$ pertenece a los conjuntos parciales de $M_{p p}$ que han podido ser añadidos a los conjuntos de modelos $M$ de $K$ que cumplen las restricciones $C$.

Dado que un elemento teórico es la mínima unidad constitutiva de una teoría empírica, ese concepto no es suficiente por sí solo para especificar intensionalmente el concepto de 'teoría empírica'. Como hemos expuesto, los científicos habitualmente no disponen sólo de una teoría general y, por lo tanto, tampoco aplican una única ley fundamental, sino que en el desarrollo de su actividad investigadora se ven obligados a recurrir a leyes y teorías fundamentales cada vez más especiales o menos generales que les permitan explicar fenómenos muy concretos del ámbito de estudio, es decir, necesitan teorías con diferentes grados de generalidad. En este sentido, cada sección de la realidad objeto de investigación, como puede ser la sección que está constituida por el sistema de la literatura, cumple, ciertamente, la ley fundamental general de la teoría correspondiente a esa sección. Pero asimismo se exige que cada una de las secciones parciales que la componen, como pueden ser las acciones literarias de producción, recepción, mediación o elaboración, además de satisfacer la ley fundamental general, debe cumplir otras leyes fundamentales especiales o menos generales (Chico Rico 1987: 57). De este modo, se puede afirmar, por ejemplo, que en el ámbito de la recepción literaria la ley fundamental válida es una ley especial con respecto a la ley fundamental aplicable a la totalidad del sistema de la literatura; y que la ley fundamental válida para el conjunto de acciones comunicativas literarias es una ley especial con relación a la ley fundamental válida en la totalidad de las acciones comunicativas estéticas. 
Al elemento teórico cuya ley fundamental es especial respecto a la ley fundamental de otro elemento teórico de una teoría empírica determinada se denomina elemento teórico especializado. Y al elemento teórico que expresa la ley fundamental de una teoría empírica se llama elemento teórico básico (Finke 1982: 161-164, 170-172). Para los distintos conjuntos parciales del ámbito de aplicación $I$ del elemento teórico básico pueden desarrollarse elementos teóricos especializados. La función de los elementos teóricos especializados consiste en limitar el contenido empírico del elemento teórico básico al ámbito parcial $I^{\prime}$ de I. Es decir, una especialización o un elemento teórico especializado aplica a un conjunto parcial de $I$ una ley fundamental especial que restringe la extensión del conjunto de los $M$ del elemento teórico básico (Finke 1982: 161; Hauptmeier/ Schmidt 1985: 52). Las afirmaciones empíricas que se pueden realizar con la ayuda de los elementos teóricos especializados y con la de los elementos teóricos básicos constituyen el contenido empírico de una teoría científica (Sneed 1976: 125). La especialización $(\sigma)$ de un elemento teórico $(T)$ puede definirse de la siguiente manera (Balzer/ Sneed 1983: 125-126): y sólo si

D 5 Siendo T' y T elementos teóricos, T' es una especialización de T (T' $\sigma \mathrm{T})$ si
(1) $M_{\mathrm{pp}}^{\prime}=\mathrm{M}_{\mathrm{pp}}$
(2) $M_{p}^{\prime}=M_{p}$
(3) $r^{\prime}=r$
(4) $M^{\prime} \subseteq M$
(5) $\mathrm{C}^{\prime} \subseteq \mathrm{C}$
(6) I' $\subseteq \mathrm{I}$.

Como se especifica en (1), (2) y (3), los componentes estructurales de $T^{\prime}$ que están constituidos por $M_{p p}^{\prime}, M_{p}^{\prime}$ y $r^{\prime}$ son idénticos a los componentes respectivos del elemento teórico básico. En cambio, los componentes estructurales de $T$ ' que están compuestos por los $M^{\prime}$, el conjunto de restricciones $C^{\prime}$ y el ámbito de aplicación $I^{\prime}$ están incluidos o son iguales a los componentes respectivos de $T$, según se señala en (4), (5) y (6). En este caso se ha seleccionado del conjunto de los $M$ un conjunto parcial $M^{\prime}$; las restricciones $C^{\prime}$ constituyen unas condiciones especiales de interpretación que aparecen implícitas en $C$, y el ámbito de aplicación $I$ ' es un conjunto parcial del ámbito de aplicación $I$ del elemento teórico básico.

Esta relación interteórica de especialización, así como también otros tipos de relaciones interteóricas como pueden ser las de teorización, reducción, equivalencia o complementación $^{11}$, desempeñan una extraordinaria importancia en la construcción de teorías científicas.

\footnotetext{
${ }^{11}$ La teorización $T$ ' de una teoría $T$ se produce, por ejemplo, cuando a $T$ se le añaden nuevos componentes teóricos. Se habla de una relación de reducción entre $T^{\prime}$ y $T$ si el contenido empírico de $T$ está incluido en el de $T^{\prime}$, y $T^{\prime}$ es considerada 'más simple' o 'mejor' que $T$ porque $T$ ' permite explicar más fenómenos. La relación de equivalencia se produce si una teoría $T$ ' puede ser reducida a otra teoría $T$, y si al mismo tiempo $T$ puede ser reducida a $T$ '. Para una
} 
Gracias a esas relaciones, una teoría empírica puede ser representada como una red teórica compuesta por un conjunto de elementos teóricos entre los que existen determinadas relaciones. De este modo, la forma lógica de las teorías empíricas se puede concebir como un conjunto estructurado de elementos teóricos que forman una red, cuyos nudos son elementos teóricos y sus hilos representan relaciones entre esos elementos. Todo elemento teórico de una teoría empírica, por consiguiente, está ligado directa o indirectamente a otros elementos teóricos. La relación que se establece entre los diferentes elementos teóricos de una red teórica es del tipo 'es-más-general-que', ya que tal red teórica es una construcción jerárquicamente ordenada de elementos teóricos donde los componentes más especializados se presentan claramente diferenciados de los más generales al modo de una estructura arborescente. Esa construcción permite la modificación y ampliación de la red teórica con elementos teóricos cada vez más especializados (Balzer/ Sneed 1983: 131 y ss.; Hauptmeier/ Schmidt 1985: 53-54; Chico Rico 1987: 59). La propuesta de cada nueva aplicación de la teoría supondrá efectivamente una modificación en la estructura de la teoría, pero no en su núcleo. Precisamente este tipo de investigaciones que conducen a continuas expansiones y especificaciones de una teoría es el equivalente estructuralista de lo que T. S. Kuhn denomina 'ciencia normal'.

El concepto de teoría empírica puede ser precisado ahora con la ayuda del concepto de red teórica. Para ello, hacen falta además los siguientes componentes: un elemento teórico $\left\langle K_{o}, I_{o}\right\rangle$, donde ', especifica que se debe de tratar de un elemento teórico básico; un conjunto $I_{p}$ de aplicaciones paradigmáticas de $\left\langle K_{o}, I_{o}\right\rangle$ —que suelen corresponder a los ejemplos y problemas principales a los que da solución el elemento teórico-, de modo que el elemento teórico básico pueda ser representado como $\left\langle K_{o}, I_{o}\right\rangle$; una red teórica paradigmática $N_{p}$, cuyos hilos representen relaciones de especialización $\sigma$ y cuyo elemento teórico básico sea específicamente $\left\langle K_{o}, I_{o}\right\rangle$; y, por último, una relación de expansión $N$ que posibilite ampliaciones sucesivas de la red $N_{p}$, unas ampliaciones que se simbolizan mediante el signo $\subseteq$. Así, el concepto de teoría empírica se puede definir de la siguiente manera (Hauptmeier/ Schmidt 1985: 54-55; Finke 1982: 179; Balzer/ Sneed 1983: 144):

D $6 \mathrm{X}$ es una teoría empírica si y sólo si hay $\mathrm{K}_{\mathrm{o}}, \mathrm{I}_{\mathrm{p}}, \mathrm{N}_{\mathrm{p}}$ y $\mathrm{N}$, de modo que:

(1) $X=\left\langle K_{0}, I_{p}, N_{p}, N\right\rangle$

(2) $\left\langle\mathrm{K}_{\mathrm{o}}, \mathrm{I}_{\mathrm{p}}\right\rangle$ es un elemento teórico de acuerdo con D3

(3) $\mathrm{N}_{\mathrm{p}}$ es una $\sigma$-red teórica con el elemento teórico básico $\left\langle\mathrm{K}_{\mathrm{o}}, \mathrm{I}_{\mathrm{p}}\right\rangle$

a) $\mathrm{N}$ es una $\sigma$-red teórica

(4) $\mathrm{N}=$ b) hay $\mathrm{I}_{\mathrm{o}}, \mathrm{I}_{\mathrm{p}} \subseteq \mathrm{I}_{\mathrm{o}}$, de modo que: $(\mathrm{N})=\left\{\left\langle\mathrm{K}_{0}, \mathrm{I}_{0}\right\rangle\right\}$

c) $\mathrm{N}_{\mathrm{p}} \subseteq \mathrm{N}$

En D6 queda definido el concepto de 'teoría empírica' y, además, desde un punto de vista diacrónico. Es decir, todo sistema teórico que contenga los componentes $K_{o}, I_{p}, N_{p}$ y $N$ 
puede concebirse como un sistema teórico dinámico, ya que posibilita lógicamente la ampliación de una red paradigmática $N_{p}$ y su transformación en la red teórica $N$. C. U. Moulines compara este concepto de teoría empírica de la visión no proposicional con un pulpo y lo describe de la siguiente manera (1982: 89):

$<\ldots>$ la cabeza del pulpo sería el núcleo; el fondo del mar, del que el pulpo obtiene su alimento, sería el campo de aplicaciones y los tentáculos representarían las leyes especiales. Para el pulpo (la teoría) sólo es vital e imprescindible su cabeza (el núcleo) y una cierta porción segura del ambiente en que vive (las aplicaciones paradigmáticas). En cambio, al pulpo (a la teoría) se le pueden cortar algunos tentáculos (leyes especiales) sin que deje de existir como pulpo (como teoría). Incluso a veces puede regenerar nuevos tentáculos (construir nuevas leyes especiales).

Con ello, el concepto de teoría empírica de la visión no proposicional se evidencia como un concepto explícitamente dinámico, en oposición al concepto estático y sincrónico de las teorías científicas de la concepción clásica, lo que presenta la extraordinaria ventaja de que una teoría pueda modificarse en el transcurso de la actividad investigadora, por ejemplo, mediante especializaciones, teorizaciones, complementaciones o reducciones, sin que su organización interna o su identidad desaparezcan. Sólo esas operaciones de especialización, teorización, etc. del núcleo de una teoría podrán ser refutadas, pero no el núcleo mismo, por lo que para poder sustituir una teoría por otra tendrá que haberse construido previamente otro núcleo teórico con su correspondiente ámbito de aplicación propuesto. Por otra parte, esta concepción de las teorías científicas permite dar una solución en un sentido constructivista a la problemática de la dicotomía ‘teórico/empírico' (Maldonado Alemán 1997). 'En resumen, la concepción estructural $\langle\ldots . .>$ se presenta como una concepción de la ciencia que toma en cuenta sus aspectos pragmáticos, holistas y diacrónicos, por oposición a la concepción heredada <o clásica>, marcada por una metodología sintáctico-semántica, atomística y puramente sincrónica" (Echeverría 1989: 151).

\section{CONCLUSIÓN}

En definitiva, con la visión no proposicional o estructural de las teorías científicas la investigación literaria dispone de un concepto de teoría científica útil y adecuado a la complejidad de su propio objeto de estudio. Siguiendo los principios fundamentales de esta concepción estructural, para la investigación empírica del sistema de la literatura, se deberá elaborar una teoría de ese sistema compuesta por una red de elementos teóricos relacionados entre sí que permitan el estudio diferenciado de las distintas secciones que lo constituyen. Para cada una de esas secciones, es decir, para las acciones literarias de producción, mediación, recepción y elaboración, se tendrá que construir respectivamente un elemento teórico especializado que estará supeditado al elemento teórico básico. La construcción de cada elemento teórico parte de la constitución previa de un ámbito de aplicación propuesto $I$, para lo que habrá que construir y describir en primer lugar la sección de la realidad compuesta por las acciones literarias de comunicación que específicamente se pretendan explicar. En esa descripción no aparece la realidad, sino un modelo de realidad construido conceptualmente. El siguiente paso consiste en elaborar la estructura lógica del elemento teóri- 
co, esto es, habrá que aportar un sistema de conceptos y axiomas que permita estructurar, describir y explicar el ámbito de aplicación $I$. La definición del ámbito de aplicación propuesto será en un principio vaga e imprecisa, y tendrá que ir delimitándose y concretándose en el transcurso del proceso de investigación. Precisamente, una parte de la actividad investigadora se dedica a determinar qué modelos parciales pueden pertenecer a $I$, pues no todas las aplicaciones previstas tendrán éxito. $I_{p}$ designa el conjunto parcial de $I$ que ha sido definido con exactitud y cuyos elementos han resultado ser modelos de la estructura lógica $K$ del elemento teórico. $I_{p}$ constituye, por tanto, las aplicaciones paradigmáticas del elemento teórico que han sido seleccionadas tras las primeras aplicaciones con éxito de éste. Qué otras aplicaciones permite el elemento teórico, lo decidirá el proceso de investigación. Por consiguiente, para construir un elemento teórico no bastará con aportar un ámbito de aplicación propuesto $I$ y un núcleo correspondiente $K$, sino que también hará falta proporcionar, tras la realización de unas investigaciones empíricas ejemplares, un conjunto mínimo de aplicaciones paradigmáticas $I_{p}$, que posteriormente pueden ir aumentando en número e importancia. En suma, el aparato conceptual global de la teoría del sistema de la literatura podrá ser introducido progresivamente a partir de la construcción de los diferentes elementos teóricos que la constituyen, hasta componer una red teórica completa.

\section{BIBLIOGRAFÍA}

AcostA, L. A. (1989), El lector y la obra. Teoría de la recepción literaria (Madrid: Gredos).

BALzer, W. (1982), Empirische Theorien: Modelle - Strukturen - Beispielen (Braunschweig/Wiesbaden: Vieweg).

BALZER, W./ H. GÖTTNER, (1983), «Eine logisch rekonstruierte Literaturtheorie: Roman Jakobson», en Balzer/ Heidelberger (eds.), 304-331.

BAlzer, W./ M. Heidelberger (eds.) (1983), Zur Logik empirischer Theorien (Berlín/Nueva York: de Gruyter).

BALzeR, W./ C. U. MOULines/ J. D. SNeEd (1987), An architectonics for science (Berlín: Springer).

BALZER, W./. J. D. SNEED (1983), «Verallgemeinerte Netz-Strukturen empirischer Theorien», en Balzer/ Heidelberger (eds.), 117-168.

BARSCH, A. (1981), Die logische Struktur linguistischer Poetiken. Vergleichende Untersuchungen auf dem Grenzgebiet zwischen Linguistik und Literaturwissenschaft (Berlín: Einhorn).

CARNAP, R. (1959), Induktive Logik und Wahrscheinlichkeit (Viena: Springer).

- (1960) «Theoretische Begriffe der Wissenschaft», Zeitschrift für philosophische Forschung, 14, 209-233 y 571-598.

- (1969), Einführung in die Philosophie der Naturwissenschaft (Múnich: Nymphenburger Verlagshandlung). 
CHICO Rico, F. (1987), «Fundamentos metateóricos de la ciencia empírica de la literatura», Estudios de Lingüística, 4, 45-61.

DIEDERICH, W. (1981), Strukturalistische Rekonstruktionen. Untersuchungen zur Bedeutung, Weiterentwicklung und interdisziplinären Anwendung des strukturalistischen Konzepts wissenschaftlicher Theorien (Braunschweig/Wiesbaden: Vieweg).

DuJ, T. A. VAN (1972), Some aspects of text grammmars. A study in theoretical linguistics and poetics (La Haya/París: Mouton).

ECHEverría, J. (1989), Introducción a la Metodología de la Ciencia. La Filosofía de la Ciencia en el siglo XX (Barcelona: Barcanova).

Feyerabend, P. (1970), Wider den Methodenzwang (Fráncfort del Meno: Suhrkamp, 1976).

FINKE, P. (1981), «A sketch of constructive functionalism», Poetics, 10, 4/5, 337-355.

- (1982), Konstruktiver Funktionalismus. Die wissenschaftstheoretische Basis einer empirischen Theorie der Literatur (Braunschweig/Wiesbaden: Vieweg).

GÖTTNER, H./ J. JAKOBS (1978), Der logische Bau von Literaturtheorien (Múnich: Fink).

GROEBEN, N. (1972), Literaturpsychologie. Literaturwissenschaft zwischen Hermeneutik und Empirie (Stuttgart: Kohlhammer).

(1980), Rezeptionsforschung als empirische Literaturwissenschaft. Paradigma- durch Methodendiskussion an Untersuchungsbeispielen (Tübingen: Narr).

(1982), «Empirische Literaturwissenschaft», en D. Hart/ P. Gebhardt (eds.), Erkenntnis der Literatur. Theorien, Konzepte, Methoden der Literaturwissenschaft (Stuttgart: Metzler), 266-297.

HACKING, I. (1988), «The participant irrealist at large in the laboratory», British Journal for the Philosophy of Science, 39, 277-294.

HANSON, N. R. (1977), Patrones de descubrimiento. Observación y explicación (Madrid: Alianza).

HAUPTMEIER, H./ S. J. SCHMIDT (1985), Einführung in die Empirische Literaturwissenschaft (Braunschweig/Wiesbaden: Vieweg).

HEMPEL, C. G. (1973), «The meaning of theoretical terms: a critique of the standard empiricist construal», en C. G. Hempel, Logic, methodology and philosophy of science (Amsterdam: North-Holland).

IHWE, J. (1972), Linguistik in der Literaturwissenschaft (Múnich: Fink).

KNORR-CETINA, K. (1984), Die Fabrikation von Erkenntnis. Zur Anthropologie der Naturwissenschaft (Fráncfort del Meno: Suhrkamp).

KuHN, T. S. (1962), Die Struktur wissenschaftlicher Revolutionen (Fráncfort del Meno: Suhrkamp, $3^{\mathrm{a}}$ ed., 1978). 
(1970), «Logik der Forschung oder Psychologie der wissenschaftlichen Arbeit?», en I. Lakatos/ A. Musgrave (eds.), Kritik und Erkenntnisfortschritt (Braunschweig: Vieweg, 1974), 1-24.

LATOUR, B./ S. WOOLGaR (1986), Laboratory life: The construction of scientific facts (Princenton).

MALDONAdo AlemÁN, M. (1981), Rationalität und Wissenschaftsfortschritt. Zur Kontroverse zwischen K. R. Popper und Th. S. Kuhn (Tesis de Licenciatura, Universidad de Colonia).

- (1994), Construcción y literatura. Elementos para una fundamentación teóricocientífica de la investigación literaria (Tesis Doctoral, Universidad de Sevilla).

- (1997), «El constructivismo radical y la investigación literaria», Revista de Filología Alemana, 5.

MaturanA, H. R. (1982), Erkennen: Die Organisation und Verkörperung von Wirklichkeit. Ausgewählte Arbeiten zur biologischen Epistemologie (Braunschweig/Wiesbaden: Vieweg, $2^{\mathrm{a}}$ ed., 1985).

- (1989), «Todo lo dice un observador», en J. Lovelock et al., GAIA. Implicaciones de la nueva biología, ed. de W. I. Thompson (Barcelona: Kairós), 63-79.

Mignolo, W. (1978), Elementos para una teoría del texto literario (Barcelona: Crítica).

MOULINES, C. U. (1982), Exploraciones metacientíficas. Estructura, desarrollo y contenido de la ciencia (Madrid: Alianza).

POPPER, K. R. (1935), Logik der Forschung (Tübingen: J.C.B. Mohr, $6^{\mathrm{a}}$ ed., 1976).

- (1962), «Die Logik der Sozialwissenschaften», en T. W. Adorno et al., Der Positivismusstreit in der deutschen Soziologie (Darmstadt/Neuwied: Luchterhand, $9^{\text {a }}$ ed., 1979), 103-123.

- (1964), «Naturgesetze und theoretische Systeme», en H. Albert (ed.), Theorie und Realität (Tübingen: J.B.C. Mohr), 43-58.

- (1965), Conjectures and refutations. The growth of scientific knowledge (Londres: Routledge and Kegan Paul, $2^{\mathrm{a}}$ ed.).

RiVAdulla RodrígueZ, A. (1986), Filosofía actual de la ciencia (Madrid: Tecnos).

RотH, G. (1991), «Die Konstitution von Bedeutung im Gehirn», en S. J. Schmidt (ed.), Gedächtnis. Probleme und Perspektiven der interdisziplinären Gedächtnisforschung (Fráncfort del Meno: Suhrkamp), 360-370.

- (1992a), «Das konstruktive Gehirn: Neurobiologische Grundlagen von Wahrnehmung und Erkenntnis», en S. J. Schmidt (ed.), Kognition und Gesellschaft. Der Diskurs des Radikalen Konstruktivismus 2 (Fráncfort del Meno: Suhrkamp), 277 336. 
- (1992b), «Kognition: Die Entstehung von Bedeutung im Gehirn», en W. Krohn/ G. Küppers (eds.), Emergenz: Die Entstehung von Ordnung, Organisation und Bedeutung (Fráncfort del Meno: Suhrkamp), 104-133.

SCHMIDT, S. J. (1980), Grundriß der Empirischen Literaturwissenschaft, vol. I: Der gesellschaftliche Handlungsbereich Literatur (Braunschweig/Wiesbaden: Vieweg).

- (1994), Kognitive Autonomie und soziale Orientierung. Konstruktivistische Bemerkungen zum Zusammenhang von Kognition, Kommunikation, Medien und Kultur (Fráncfort del Meno: Suhrkamp).

SNEED, J. D. (1971), The logical structure of mathematical physics (Dordrecht/Boston/Londres: Reidel).

- (1976), «Philosophical problems in the empirical science of science: A formal approach», Erkenntnis, 10, 115-146.

SPINNER, H. F. (1974), Pluralismus als Erkenntnismodell (Fráncfort del Meno: Suhrkamp).

STEGMÜLLER, W. (1973), Probleme und Resultate der Wissenschaftstheorie und analytischen Philosophie, vol. II: Theorie und Erfahrung, Zweiter Halbband: Theorienstrukturen und Theoriendynamik (Berlín/Heidelberg/Nueva York: Springer).

- (1975), «Structures and dynamics of theories: some reflections on J. D. Sneed and T. S. Kuhn», Erkenntnis, 9, 75-100.

- (1979), The structuralist view of theories (Berlín/Heidelberg/Nueva York: Springer).

(1980), Neue Wege der Wissenschaftsphilosophie (Berlín/Heidelberg/Nueva York: Springer). 